\title{
Application of Theory and Practice Integration Teaching in C Programming Language Course
}

\author{
Yu-qiao Meng \\ Jilin Teachers Institute of Engineering and Technology, changchun, 130052. China
}

\begin{abstract}
The C programming language course is a basic course in colleges and universities, whose key teaching points differ slightly with the arrangement of the specialized courses. This paper proposed an integration teaching method based on the characteristics of the $\mathrm{C}$ programming language course itself, combining theory instruction with practice teaching. The students are trained while learning. Thus, the students are able to get their ability in practice trained and improved when they acquire the theoretical knowledge.

Index Terms - theory and practice integration, $\mathrm{C}$ programming language, teaching design, teaching methodology
\end{abstract}

\section{Present Situation of C Programming Language Teaching}

The $\mathrm{C}$ programming language course is the first programming language course for the students upon they are admitted into colleges and universities. When learning $\mathrm{C}$ programming language, the students have to convert daily expressions into complex and abstract language symbols and form a habit of logic thinking. This is quite difficult for a beginner. They may find it harder and harder to comprehend as the degree of the knowledge difficulty increases and the complexity of the questions are deepened. It's not easy for the students to improve their ability to acquire the knowledge as they attach much attention to theory but little to practice because of the limited course hours and other objective factors. Gradually, they lose interest and get lost when they fail to find the practicability of the "boring" course. To tell the truth, the $\mathrm{C}$ programming language course is indeed boring to a degree, and its knowledge is difficult to be understood, but $\mathrm{C}$ programming language is of high practicability, and is widely recognized and used in the society. However, the students are poor in the mastery and application. The reason for the phenomenon, from the angle of teaching, is that there are problems in the teaching philosophy and methods as well as the testing methods, etc. Similar to most courses, more time is allocated to theory instructions, and less to experiments. What's worse, the centralized examination mechanism causes the students to spend more time and energy on the theory, and practice quite a little. They only care about the scores rather than their ability. Thus, in order to make $\mathrm{C}$ programming language teaching serve the practical purpose, we have to reform the teaching philosophy and methods, only through which can we cultivate specialized talents to meet the urgent technology requirements of the society.

\section{Meaning and Superiority of Theory and Practice Integration Teaching}

Theory and practice integration teaching is a new teaching mode in which theory, experiments and practice are combined in a scientific way. It breaks the bonds of traditional teaching manner where theory and practice are separated from each other. Theory instructions, experiment guidance, and practice teaching are integrated and complementary with each other, and all of these can be accomplished by one teacher. The teaching mode is rich and varied in contents arrangement, featuring progressive and centralized instructions; and enabling the course to go forward smoothly step by step. The teacher teaches and guides the students simultaneously at a laboratory, and the students practice while learning. Both the students and teachers can achieve and finish the teaching goals and tasks effectively through the visual and abstract teaching and theory-and-practice interacting learning. The integration teaching combines instruction and operation scientifically, allows the student to learn actively instead of passively, and arouses the students' interests in learning. Actually, the integration teaching refers to the integration of a teacher's knowledge, skills and teaching abilities, encouraging the teacher to research proper and advanced teaching methods continuously. Therefore, the teacher can have his/her teaching level improved as he/she acquires advanced knowledge, new technology and products to meet the teaching demands.

\section{Theory and Practice Integration Teaching Implement of C Programming Language Course}

\section{A. Teaching Design}

The specific implementation of $\mathrm{C}$ programming language course theory and practice integration teaching should be arranged in accordance with the different teaching stages and the teaching contents. Firstly, a basic principle to follow in teaching is to complete the learning contents in accordance with the requirements of the outline; Secondly, teachers should make the teaching contents and methods arrangement of an entire semester at the beginning of the semester, including theory and practice arrangement, project tasks, and so on at different stages; finally, the examinations at the end of the semester should be able to test the students' practical ability.

According to the characteristics of the $\mathrm{C}$ programming language course, the whole course can be divided into two parts to complete in the actual teaching. In the early period, theory instruction is primary and experiment design is auxiliary; in the middle and late period, theory and practice are 
supplementary to each other to complete the teaching contents. The contents of the early period involve some basic $\mathrm{C}$ programming language knowledge; especially first 2 or 3 chapters of the textbooks. It is the basis of all designs; therefore, as for this part, the instruction of the theoretical knowledge should be emphasized, and supplemented by the experimental practice of knowledge points to deepen the grasp of the basic knowledge. However, the problem of this part is that the contents are boring, and that as beginners, the students may be easily influenced by negative emotions; these may cause them to lose interests in subsequent learning, so the application of the teaching method in the early-period teaching is a tough problem. At the middle and late stage, students have a overall understanding of the course. As for this period, the main job is to let students persevere, learn in order to practice; and to use project and practice designs to promote the students' understanding and mastery of the knowledge, and to have their skill improved further.

\section{B. Teaching Methodology}

In the theory and practice integration teaching of the $\mathrm{C}$ programming language course, teachers can adopt a variety of teaching methods in order to achieve better learning effect. The early period teaching mainly explains the theoretically knowledge, so we could adopt the module method, namely classifying the learning contents into categories with different functions, such as the initializing definition category, input and output category, selective category and so on; then supplement the teaching by using courseware and software to demonstrate the meanings and functions. During the teaching, we could require the students to verify the instructed contents; For each different schedule, teachers can allow students to complete other designs to promote their understanding and mastery of the contents. This can make students understand the purpose and application of the study directly through the senses. The teacher teaches as the students learn and practice. The students may become "skillful with their hands" when practicing. In the middle and late period of learning, as the difficulty increases in teaching, the students may encounter a study plateau and become frustrated. At this stage, we may take the case teaching method to arouse their learning enthusiasm, and help them build up learning confidence. Teachers can introduce different cases in teaching according to different contents. Before introducing a case, teachers need to briefly explain the involved knowledge points, and then teachers put forward specific requirements for the students to complete the design themselves. According to the case complexity, students can finish their task individually or in group, but no matter in what kind of way, teachers are expected to do a targeted summary and guidance, and explain the knowledge points further. During the whole course of teaching, teachers can combine the multiple teaching methods. As for a certain question, teachers can encourage students to practice by inferring other things from one fact; and also can adopt the task driving method for teaching, requiring students to accomplish a specified task in a specified time. All in all, teachers should adopt different methods according to different teaching progresses and contents, as well as the students' real-time mastery situations. In this way, we can get twice the result with half the effort in the theory and practice integration teaching.

\section{Way of Examination}

The theory and practice integration teaching mode itself is focused on the cultivation of students' practical ability; therefore, we should try to achieve a balance between theory and practice for examinations. We can adopt a "20\% + 40\%+ $40 \% "$ mode for the comprehensive performance evaluation. $20 \%$ refers to the students' usual results, concerning their practice performance at class, including individual accomplishments, teamwork projects, etc.; this part reflects students' performance of the entire semester. The theory test accounts for $40 \%$, aiming to check student's mastery of the theoretical knowledge of the course; it's finished at the final stage of a semester, in the written form. Basic and key theoretical knowledge is mainly examined in the test. The skill test accounts for $40 \%$, also finished at the final stage of a semester; the purpose of this examination is to test students' practical ability. Students are required to complete a specified comprehensive design task within a fixed time. Such a theory and practice integration testing mode can check the teaching effect comprehensively.

\section{Integration Fostering of Teachers}

The theory and practice integration teaching is a learning, and mutually promoting progress, between teachers and students, as well as students and students. The teacher plays an important role in the integration teaching. "Integration" teacher fostering is the premise of effective integration teaching. The integration teacher of the $\mathrm{C}$ programming language course should attach much importance to project construction, and to guidance to students during teaching. The introduced cases for teaching is put forward by teachers at appropriate time; and teachers also take part in the design. To design a case, moderate in difficulty, that can form a connecting link between the preceding and the following, teachers are acquired to be able to master the key and difficult knowledge and understand the conditions of the students. In the process of teaching, apart from instructing the theory, teachers also need to correct and guide students' operation. When it comes to a specified case, teachers are expected to hold the overall situation, do the basic work well, and offer suggestions to prevent students from going in the wrong direction; and at the end of a case, teachers should draw a conclusion, and help students digest the theoretical knowledge and grasp the practical operation. The theory and practice integration teaching is a challenge for teachers' ability in the specialized skill, project guidance, project practice, etc. Thus teachers' integration fostering is the key to the success of the theory and practice integration teaching.

\section{Conclusion}

When applying the integration teaching in the $\mathrm{C}$ programming language course, teachers should make good teaching designs, adopt multiple teaching methods, arrange 
theory and practice teaching well in accordance with the teaching contents, improve the "integration" ability, and check the teaching effect in a timely and comprehensive manner through examinations so as to cultivate specialized talents that can meet their own development needs, as well as the social needs.

\section{References}

[1] Wen-Ming Xie, "On the Teaching Mode of Theory and Practice Integration under School and Enterprise Cooperation Mechanism", Vocational And Technical Education,vol.32,no.17,2011.

[2] Yi-MinYang, "Reflections on the Implementation of the Theory and Practice Integration Teaching Mode of Computer Courses", Secondary vocational education, vol.727,2013.

[3] Mei-Qin Li, "Exploration and Practice of the Theory and Practice Integration Teaching Mode ", Journal of Tianjin Vocational Institutes, vol 14,no.8,Aug.2012.

[4] Xiao-Na Zhang, "Application of Theory and Practice Integration Teaching in VB Courses", China New Technologics Products, no.11, 2012. 